\title{
Welcome the \\ Canadian Association of Gastroenterology
}

he Canadian Journal of Gastroenterology was launched in October 1987 to
provide an international forum for clinical and scientific articles in gastroenterology and hepatology. The Journal is listed in Current Contents and other major indexing/abstracting services.

We welcome the adoption of the Journal as the official organ of the Canadian Association of Gastroenterology and look forward to publishing CAG news, information and letters to the Editor. We encourage members to contribute articles for publication in their journal.

The editorial policy has been, from the outset, focused, rapid review and publication of new and important clinical topics in gastroenterology and hepatology. The Journal also provides a vehicle for discussion of irksome, provocative and sometimes dangerous developments in the ethics, practice and politics of this constantly changing field. A truly international editorial board brings expertise, flavour and direction to the Journal.

In addition to the six regular issues published each year, special, topic-specific editions are frequently published, eg, on therapeutic endoscopy and inflammatory bowel disease.

In response to the environmental movement, the journal is printed entirely on recycled paper using vegetable-based inks.

The Journal welcomes original clinical and basic science articles, clinical trial reports, in-depth review articles, brief communications and unique case reports in either English or French. 


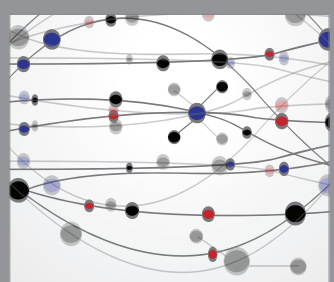

The Scientific World Journal
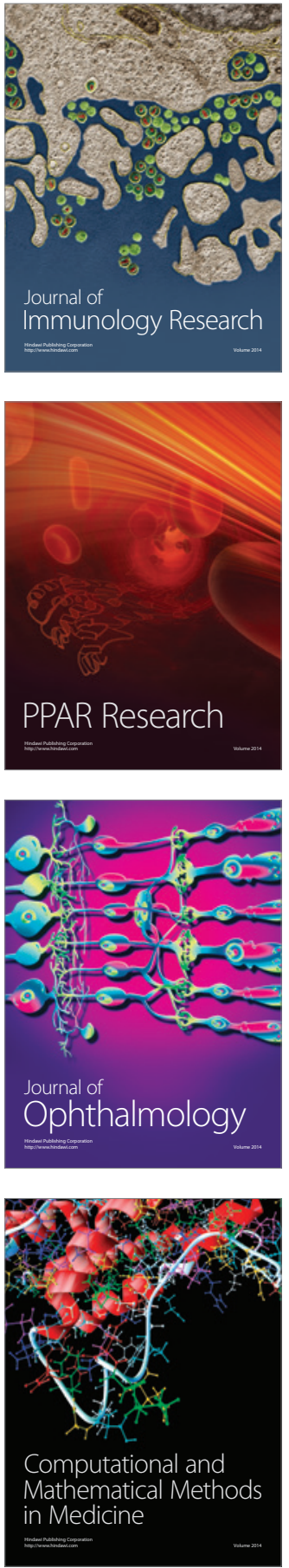

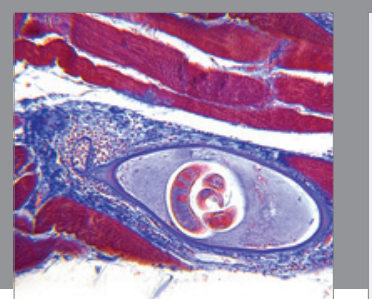

Gastroenterology Research and Practice

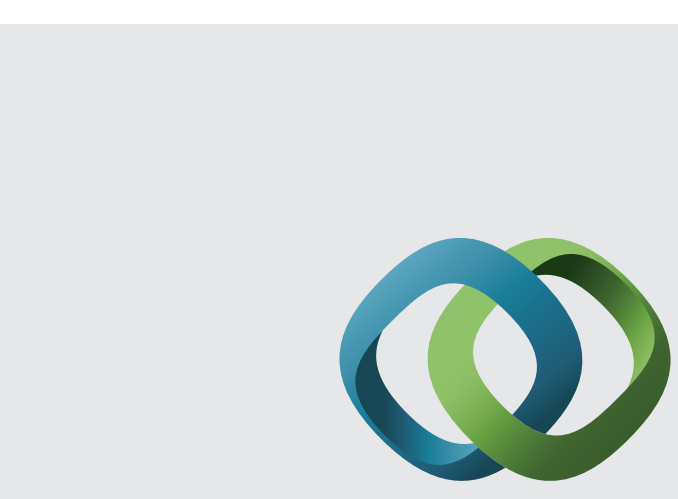

\section{Hindawi}

Submit your manuscripts at

http://www.hindawi.com
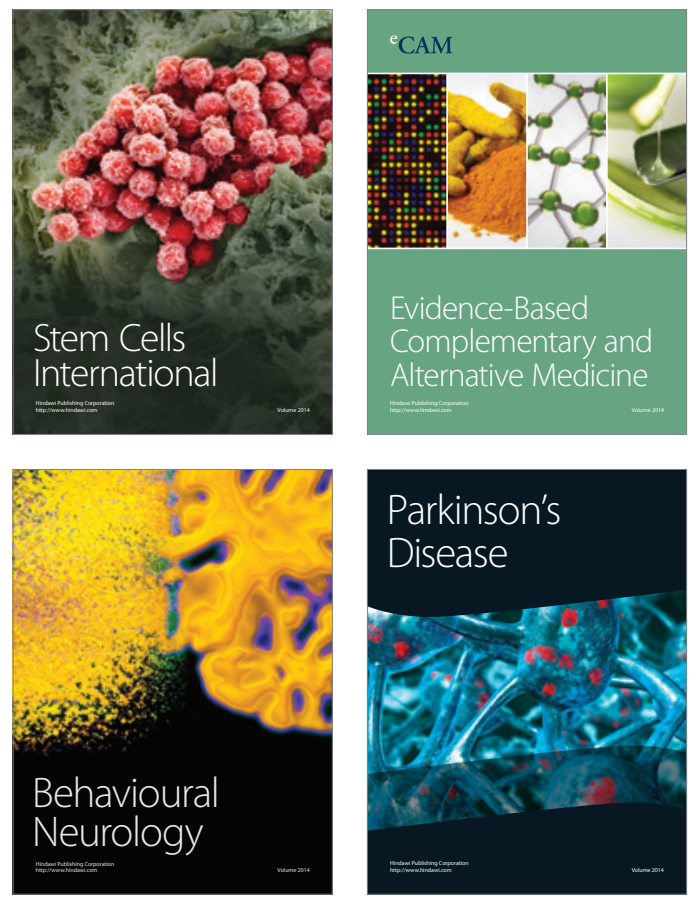
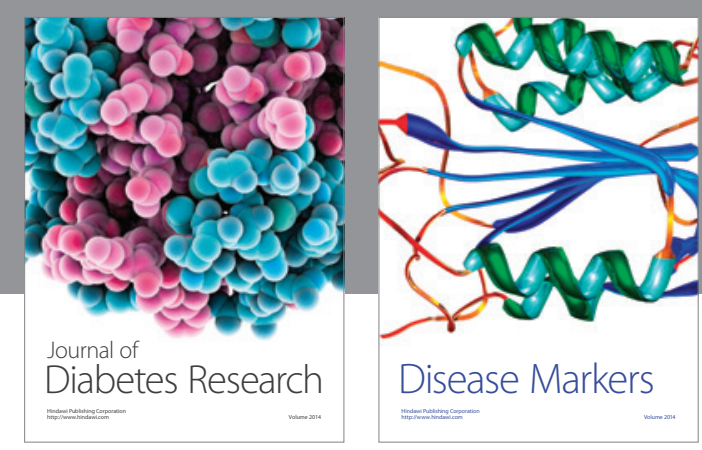

Disease Markers
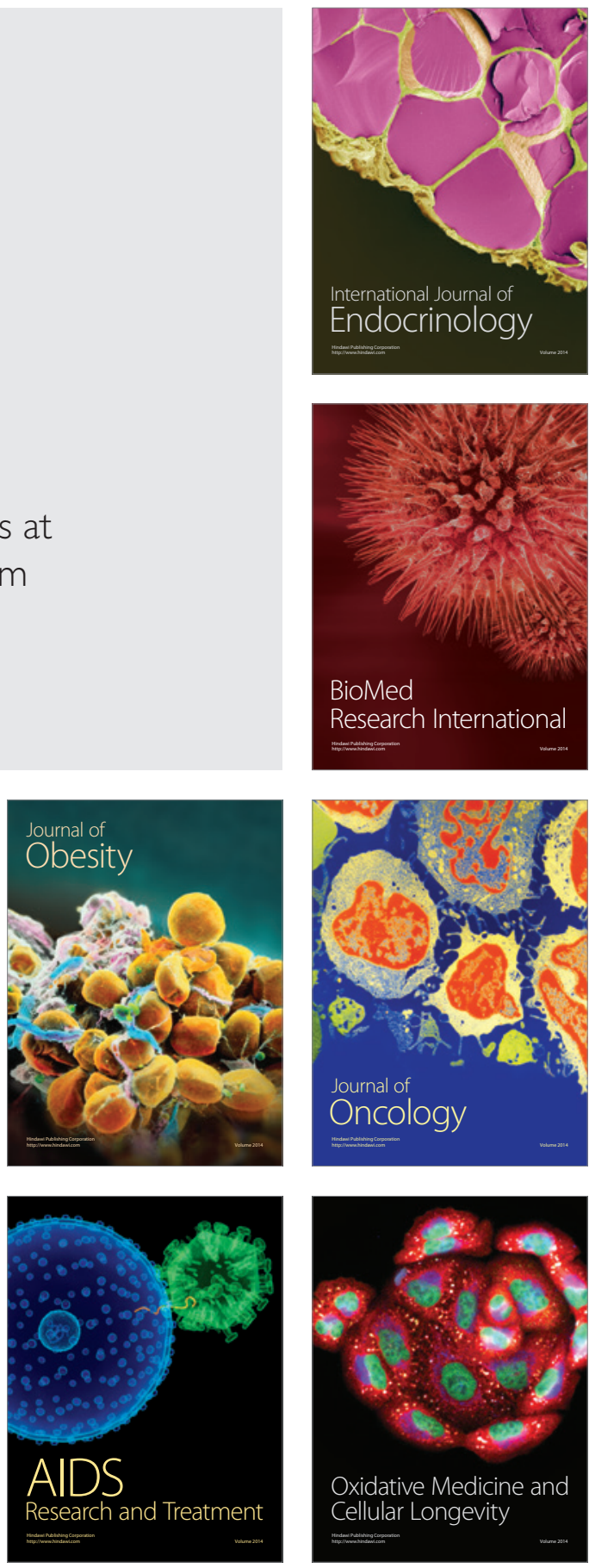